\title{
Identification of novel tylosin analogues generated by a wblA disruption mutant of Streptomyces ansochromogenes
}

\author{
Cheng Lu, ${ }^{1,2}$ Guojian Liao ${ }^{3}$, Jihui Zhang ${ }^{1 *}$ and Huarong Tan ${ }^{1 *}$
}

\begin{abstract}
Background: Streptomyces, as the main source of antibiotics, has been intensively exploited for discovering new drug candidates to combat the evolving pathogens. Disruption of $w b / A$, an actinobacteria-specific gene controlling major developmental transition, can cause the alteration of phenotype and morphology in many species of Streptomyces. One wblA homologue was found in Streptomyces ansochromogenes 7100 by using the Basic Local Alignment Search Tool. It is interesting to identify whether novel secondary metabolites could be produced by the wblA disruption mutant as evidenced in other Streptomyces.

Results: The wblA disruption mutant of S. ansochromogenes 7100 ( $\triangle$ wb|A) was constructed by homologous recombination. $\triangle$ wblA failed to produce spores and nikkomycin, the major product of S. ansochromogenes 7100 (wild-type strain) during fermentation. Antibacterial activity against Staphylococcus aureus and Bacillus cereus was observed with fermentation broth of $\triangle$ wblA but not with that of the wild-type strain. To identify the antibacterial compounds, the two compounds (compound $\mathbf{1}$ and compound $\mathbf{2}$ ) produced by $\triangle$ wblA were characterized as 16-membered macrolides by mass spectrometry and nuclear magnetic resonance spectroscopy. The chemical structure of these compounds shows similarity with tylosin, and the bioassays indicated that the two compounds inhibited the growth of a number of gram-positive bacteria. It is intriguing that they displayed much higher activity than tylosin against Streptococcus pneumoniae.
\end{abstract}

Conclusions: Two novel tylosin analogues (compound $\mathbf{1}$ and $\mathbf{2}$ ) were generated by $\Delta$ wblA. Bioassays showed that compound $\mathbf{1}$ and $\mathbf{2}$ displayed much higher activity than tylosin against Streptococcus pneumoniae, implying that these two compounds might be used to widen the application of tylosin.

Keywords: wblA, Nikkomycin, Tylosin analogues, Streptomyces ansochromogenes, Bioassay

\section{Background}

The crisis of antibiotic resistance has become an impending global problem, so novel antibiotics are required to combat the evolving pathogens and new emerging diseases. More than half of medically important antimicrobial and antitumor antibiotics are produced by Streptomyces. Genome engineering and gene manipulation on secondary metabolic gene clusters have been widely applied for exploring novel bioactive agents. For

\footnotetext{
*Correspondence: zhang.jihui@im.ac.uk; tanhr@im.ac.cn

1 State Key Laboratory of Microbial Resources, Institute of Microbiology,

Chinese Academy of Sciences, Beijing 100101, China

Full list of author information is available at the end of the article
}

example, using heterologous expression, a $157 \mathrm{~kb}$ daptomycin biosynthetic gene cluster from Streptomyces roseosporus NRRL 15998 was successfully cloned and heterologously expressed in Streptomyces coelicolor [1]. Two hybrid antibiotics were generated by genetic manipulation of the nikkomycin and polyoxin biosynthetic gene clusters [2]. Supplementation of the mutasynthesis strain with nicotinic acid led to the production of two novel nikkomycin analogues [3]. However, sequencing of several Streptomyces genomes revealed that a large number of antibiotic biosynthetic gene clusters are present, which have the potential to produce many more natural products than had previously been recognized [4-7]. 
Therefore, it has become necessary to devise methods and strategies to identify valuable natural products. One of the features of antibiotic synthesis in Streptomyces is that the production of antibiotics is generally associated with the development and differentiation of Streptomyces. Genetic manipulations of pleiotropic regulators responsible for both differentiation and antibiotic production may effectively influence the expression of certain genes involved in metabolic pathways, thus it would be an efficient strategy for searching novel metabolites. By this approach, comprehensive elucidations on biosynthetic pathways or regulatory mechanisms of the metabolite biosynthesis could be circumvented.

whi genes are involved in the life cycle of Streptomyces as well as in the production of various antibiotics [8]. Disruption of these genes resulted in white phenotype of aerial hyphae in Streptomyces, so they were named as whi genes. whiB gene was originally discovered in Streptomyces coelicolor, and whiB-like $(w b l)$ genes are widespread in Streptomyces $[9,10]$. There are at least 11 homologues of $w h i B$ genes on the chromosome of $S$. coelicolor. Mutation or absence of $w b l A$ caused multiple effects on Streptomyces, such as the failure of sporulation, enhancement of actinorhodin, undecylprodigiosin, doxorubicin, tautomycetin, and moenomycin production [9, 11-13]. Therefore, WblA is recognized as a global regulator. It plays as a repressor of antibiotic production in S. coelicolor, but acts as a pivotal activator for natamycin biosynthesis in Streptomyces chattanoogensis L10 [14]. Streptomyces ansochromogenes 7100, a natural peptidyl nucleoside antibiotic nikkomycin producer, has been studied for decades [15]. Like other well-studied Streptomyces, it has a typical life cycle of differentiation and development with aerial mycelia and spore formation accompanied by secondary metabolites biosynthesis. In search of the sequenced genome of $S$. ansochromogenes, a whiB-like gene situated on the chromosome was found and its encoding protein shares $96 \%$ identity with WblA in S. coelicolor, likewise it was named as wblA (gene accession number KT583835).

In this study, we focused on the secondary metabolites produced by the wblA disruption mutant of $S$. ansochromogenes 7100 ( $\Delta$ wblA). It is intriguing that $\Delta$ wblA failed to produce nikkomycin but led to the discovery of novel active metabolites simultaneously. These compounds were subsequently isolated, purified and analyzed for their structures and bioactivities against a number of bacteria.

\section{Results}

\section{Construction of wblA disruption mutant and its complementation}

In order to identify whether the metabolite profile could be affected by wblA disruption in S. ansochromogenes
$7100, \Delta$ wblA was constructed via homologous recombination. As expected, $\Delta$ wblA failed to form grey spores and spore chains on minimal medium (MM) agar in comparison with wild-type (WT) strain (Fig. 1a-c). On the other hand, nikkomycin, the only secondary metabolite identified so far from this strain, was examined. Cultures from the same time-course experiments were subjected to bioassays against Alternaria longipes and Candida albicans for nikkomycin activity test (Fig. 2a, b). In contrast to WT strain, no inhibition zone was observed against above two indicator strains with the fermentation filtrate of $\Delta$ wblA. High-performance liquid chromatography (HPLC) analysis demonstrated that the production of nikkomycin was completely abolished in $\Delta$ wblA (Fig. 2c). To further verify the effect of wblA disruption on nikkomycin production, the transcription profile of genes involved in nikkomycin biosynthesis was analyzed by quantitative Real Time Polymerase Chain Reaction (qRT-PCR). The biosynthetic gene cluster of nikkomycin includes one pathway-specific regulatory gene $(\operatorname{san} G)$ and 21 structural genes consisting of three transcriptional units (sanO- $V$, sanN-I and sanF-X) [16]. The first gene of each transcriptional unit was chosen to examine the transcription of corresponding genes. The results showed that transcriptions of $\operatorname{san} G$ and other three genes $(\operatorname{sanN}$, $\operatorname{san} O$ and $\operatorname{sanF}$ ) situated in each transcriptional unit were all not detected in $\triangle \mathrm{wblA}$, whereas the transcription of $h r d B$ as internal control, encoding the principal sigmalike factor, was not affected by the disruption of wblA (Fig. 2d). Complementary experiment was performed by integrating a copy of $w b l A$ and pSET152 vector into the chromosome of $\Delta$ wblA, respectively. As expected, nikkomycin production in $\triangle$ wblA was restored as that in WT strain (Fig. 2a-c). These results demonstrated that wblA is essential for nikkomycin biosynthesis in S. ansochromogenes 7100. Disruption of this gene affected not only the spore formation but also the nikkomycin biosynthesis, implying that $w b l A$ possesses multiple functions.

\section{Analyses of the secondary metabolites of $\Delta \mathrm{wblA}$}

Based on the fact that nikkomycin production was abolished in $\triangle \mathrm{wblA}$, it is noteworthy to identify whether new products could be produced by $\Delta$ wblA. The culture filtrates from the different time-course experiments were subjected to bioassays against representative gram-positive bacteria and gram-negative bacteria (Additional file 1: Table S1). The culture filtrate collected from $\Delta$ wblA after incubation for $96 \mathrm{~h}$ showed clear inhibition zones against both Staphylococcus aureus and Bacillus cereus, whereas no inhibition zone was found in the culture filtrate from WT (Fig. 3a, b). Chloroform extracts from these cultures were further analyzed by HPLC (Fig. 3c), and distinct peaks appeared at $17 \mathrm{~min}$ (compound $\mathbf{1}$ ) and 
a

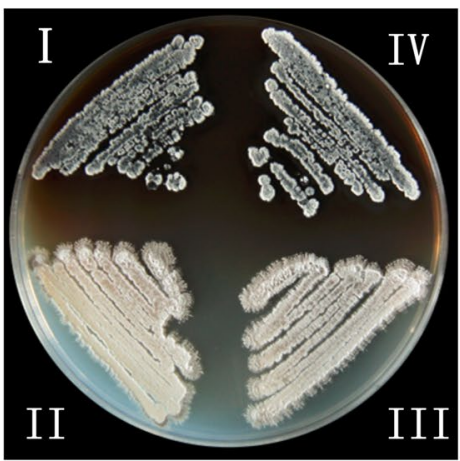

Front side b

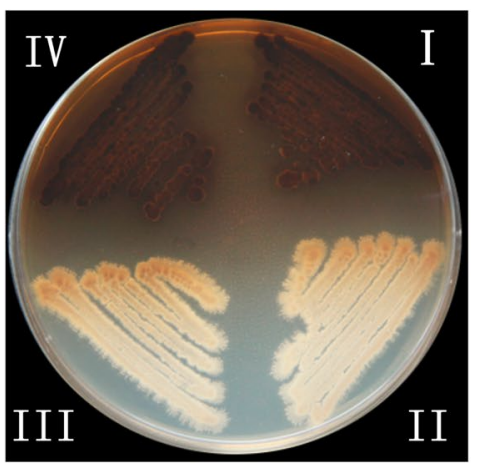

Reverse side
C

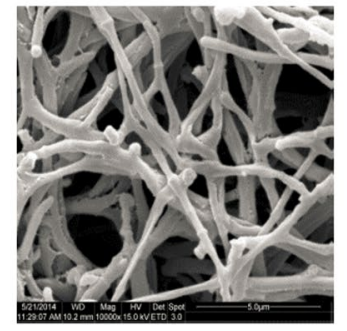

II

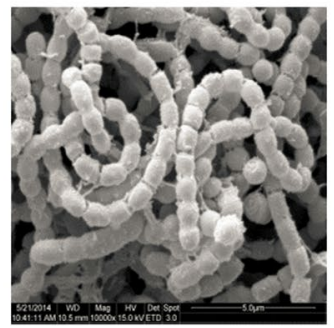

III

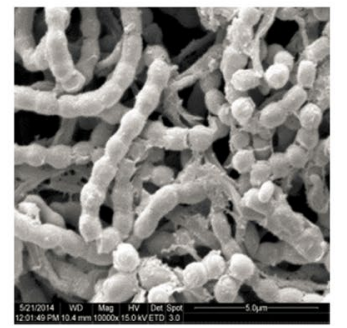

IV

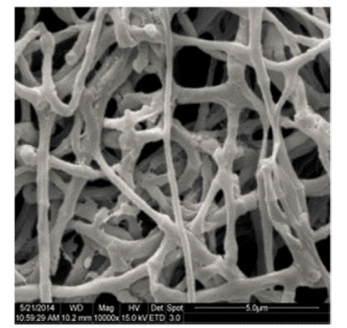

Fig. 1 Effects of wblA disruption on the phenotype and morphological differentiation of S. ansochromogenes 7100. Observations on the phenotype of S. ansochromogenes 7100 and its derivatives from both sides of the plate $(\mathbf{a}, \mathbf{b})$, and the scanning electron micrographs of the mycelia and spores (c). (I): $\triangle \mathrm{wblA}$, (II): S. ansochromogenes 7100, (III): complemented strain by integrating a copy of wblA into the chromosome of $\triangle \mathrm{wblA}$, (IV): the control strain by integrating PSET152 vector into the chromosome of $\triangle \mathrm{wbIA}$

18 min (compound 2) in the extract of $\Delta$ wblA (Fig. 4a). Both compounds gave rise to distinctive absorption at wavelength $286 \mathrm{~nm}$ on the ultra-violet (UV) spectra (Fig. 4b), indicating that they might be new products generated by $\Delta$ wblA since these two compounds were not found in WT under the same conditions.

\section{Isolation and structural analyses of compound 1 and 2}

To determine the chemical structures of compound $\mathbf{1}$ and 2, 18 liters of fermentation broth of $\Delta$ wblA in SP medium was harvested and extracted with chloroform. The organic phase was concentrated and applied onto Sephadex LH-20 column for further purification. $2.3 \mathrm{mg}$ of compound 1 and $5.2 \mathrm{mg}$ of compound $\mathbf{2}$ were obtained after final separation by semi-preparative HPLC. The chemical structures of these two compounds were determined by Mass Spectrometry (MS) and Nuclear Magnetic Resonance (NMR) spectroscopy.

High resolution positive-ion electron spray ionization mass spectrometry (HR-ESI-MS) of compound $\mathbf{1}$ gave a molecular ion peak at $m / z 577.33459\left(\left[\mathrm{M}+\mathrm{Na}-\mathrm{H}_{2} \mathrm{O}\right]^{+}\right)$ and the molecular formula was found to be $\mathrm{C}_{29} \mathrm{H}_{48} \mathrm{O}_{11}$.
An initial survey of ${ }^{1} \mathrm{H}$ NMR and ${ }^{13} \mathrm{C}$ NMR spectra (Fig. 5a, b) indicated the existence of two conjugated double bonds, a mycinose moiety and two carbonyl carbons $\left(\delta_{\mathrm{C}} 174.7\right.$ and $\left.204 \mathrm{ppm}\right)$. Cross peaks between $\delta_{\mathrm{H}}(4.98$, 1.92 and $2.5 \mathrm{ppm}$ ) and $\delta_{\mathrm{C}} 174.7 \mathrm{ppm}$ on HMBC indicated that compound 1 could contain a macrolide backbone. Along with other correlations (Additional file 1: Figure S1) between protons and carbons on HMBC, HSQC and ${ }^{1} \mathrm{H}-{ }^{1} \mathrm{H}$ COSY, compound $\mathbf{1}$ seemed to be an analogue of tylosin, and most signals on the lactone and mycinose moiety could be assigned based on the NMR data of tylosin, except those at positions C5 and C6 [17]. Proton and carbon resonances for the two sugar moieties at C5 and acetaldehyde group at C6 in tylosin were absent, but two additional hydroxyl groups were present as indicated by the two sets of signals $\left(\delta_{\mathrm{H}} 4.1, \delta_{\mathrm{C}} 71.6 \mathrm{ppm} ; \delta_{\mathrm{H}}\right.$ 4.3, $\left.\delta_{\mathrm{C}} 67.9 \mathrm{ppm}\right)$, which were determined by the following analysis. A cross peak between $\mathrm{H} 4\left(\delta_{\mathrm{H}} 1.48 \mathrm{ppm}\right)$ and $\delta_{\mathrm{H}} 4.1 \mathrm{ppm}$ on ${ }^{1} \mathrm{H}-{ }^{1} \mathrm{H}$ COSY indicated that $\delta_{\mathrm{H}} 4.1 \mathrm{ppm}$ and $\delta_{\mathrm{C}} 71.6 \mathrm{ppm}$ could be assigned to $\mathrm{C} 5$; while the correlation between $\delta_{\mathrm{H}} 4.3 \mathrm{ppm}$ and $\delta_{\mathrm{C}} 71.6 \mathrm{ppm}$ on HMBC suggested that $\delta_{\mathrm{H}} 4.3 \mathrm{ppm}$ and $\delta_{\mathrm{C}} 67.9 \mathrm{ppm}$ could be 
a

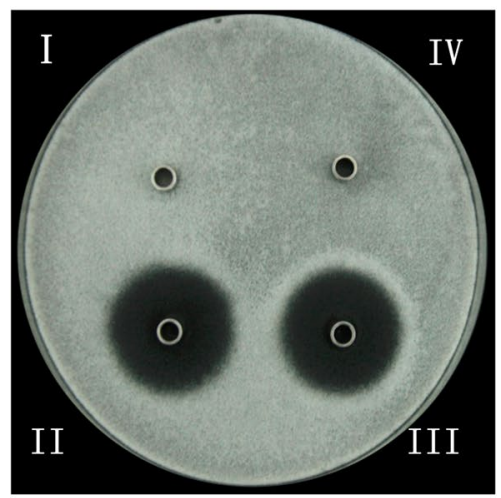

C
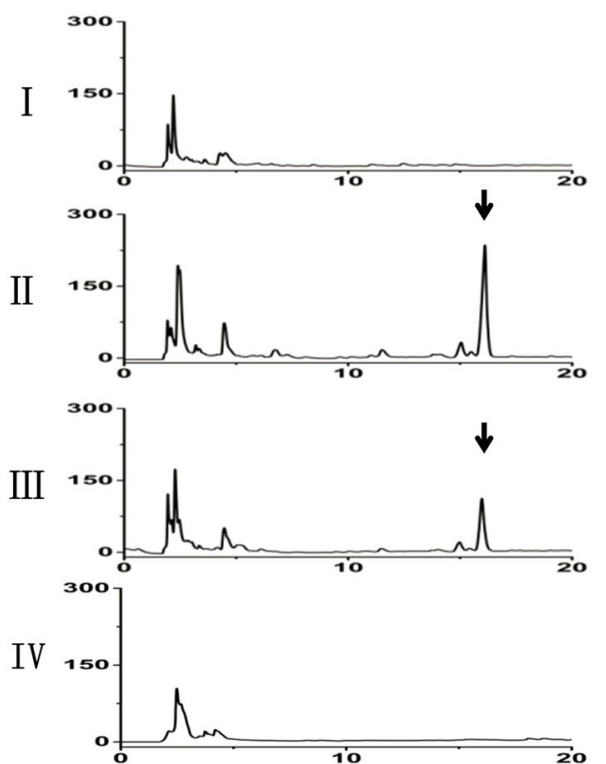

b

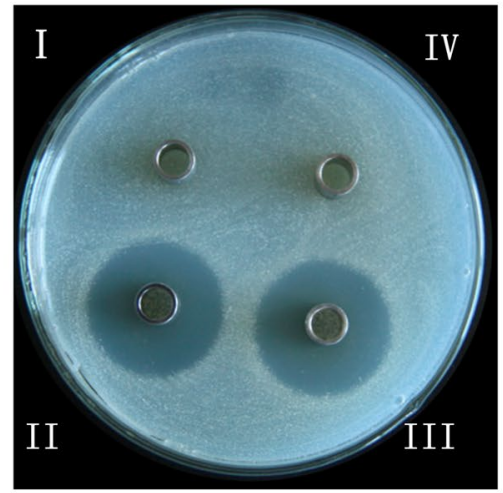

d

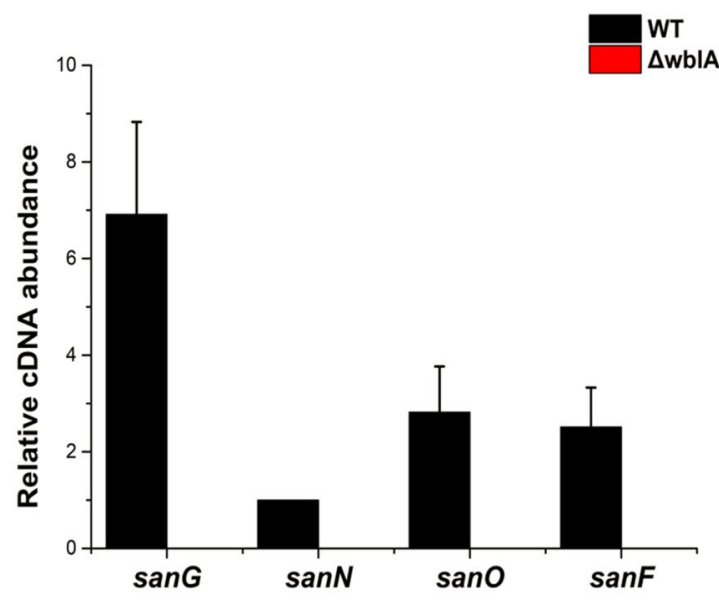

Fig. 2 Effects of wblA disruption on nikkomycin production. a The bioassay of nikkomycin against Alternaria longipes. b The bioassay of nikkomycin against Candida albicans. c HPLC analysis of nikkomycin. $\mathbf{d}$ Transcription analysis of genes related to nikkomycin biosynthesis by qRT-PCR; the transcript of $h r d B$ was used as an internal control. (I): $\triangle$ wbIA, (II): S. ansochromogenes 7100, (III): complemented strain by integrating a copy of wblA into the chromosome of $\triangle \mathrm{wbIA}$, (IV): the control strain by integrating pSET152 vector into the chromosome of $\triangle \mathrm{wb} / \mathrm{A}$. Arrows indicate the peak of nikkomycin on HPLC produced by S. ansochromogenes 7100

assigned to C6. Combined with other NMR data, compound 1 was determined as 6-hydroxy-21-O-mycinosyltylactone (Fig. 5c), a novel tylosin analogue.

For compound 2, HR-ESI-MS gave a molecular ion peak at $m / z 602.38965\left(\left[\mathrm{M}+\mathrm{NH}_{4}\right]^{+}\right)$and the molecular formula was found to be $\mathrm{C}_{31} \mathrm{H}_{52} \mathrm{O}_{10}$. Comparison of the ${ }^{1} \mathrm{H}$ NMR and ${ }^{13} \mathrm{C}$ NMR data (Fig. 5d, e) with those of compound $\mathbf{1}$ indicated a highly structural similarity between the two compounds, and the only difference is at C6. $\delta_{\mathrm{H}} 4.3 \mathrm{ppm}$ and $\delta_{\mathrm{C}} 67.9 \mathrm{ppm}$ at $\mathrm{C} 6$ were absent and the chemical shift at C6 was high-field shifted to $\delta_{\mathrm{C}}$ $38 \mathrm{ppm}$ in compound 2. Meanwhile, two sets of extra signals $\left(\delta_{\mathrm{C}} 22.7 \mathrm{ppm}\right.$ and $\delta_{\mathrm{H}} 1.62 \mathrm{ppm} ; \delta_{\mathrm{C}} 9.4 \mathrm{ppm}$ and $\delta_{\mathrm{H}}$ $0.92 \mathrm{ppm})$ showed the existence of an ethyl group, while the correlation between $\delta_{\mathrm{H}} 0.92 \mathrm{ppm}$ and $\mathrm{C} 6\left(\delta_{\mathrm{C}} 38 \mathrm{ppm}\right)$ confirmed that the ethyl group is attached to C6. Further analysis of the HMBC, HSQC and COSY data (Additional file 1: Figure S2), compound 2 was determined as another tylosin analogue and designated as $23-\mathrm{O}-\mathrm{myci}-$ nosyltylactone (Fig. 5f).

The NMR spectroscopic data of compound $\mathbf{1}$ and compound $\mathbf{2}$ are summarized in Table 1 . The structural differences among compound $\mathbf{1}, \mathbf{2}$ and tylosin are illustrated (Fig. 5g). 
a

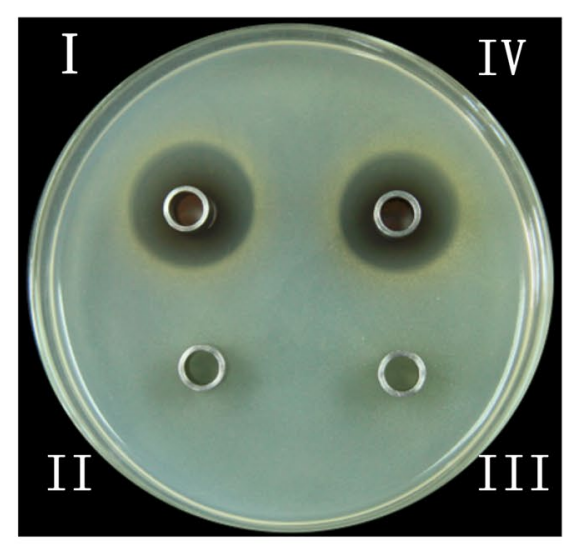

\section{b}

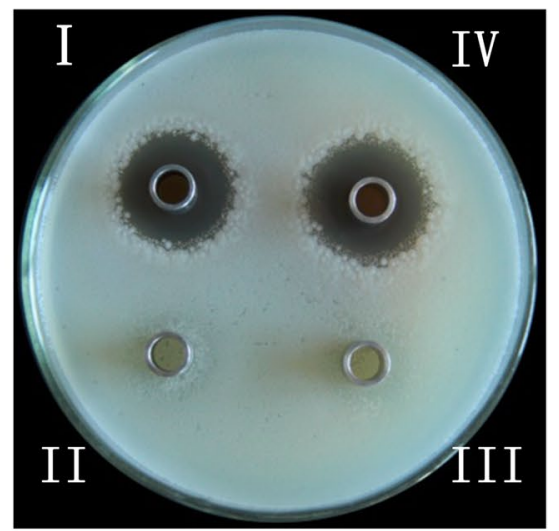

C
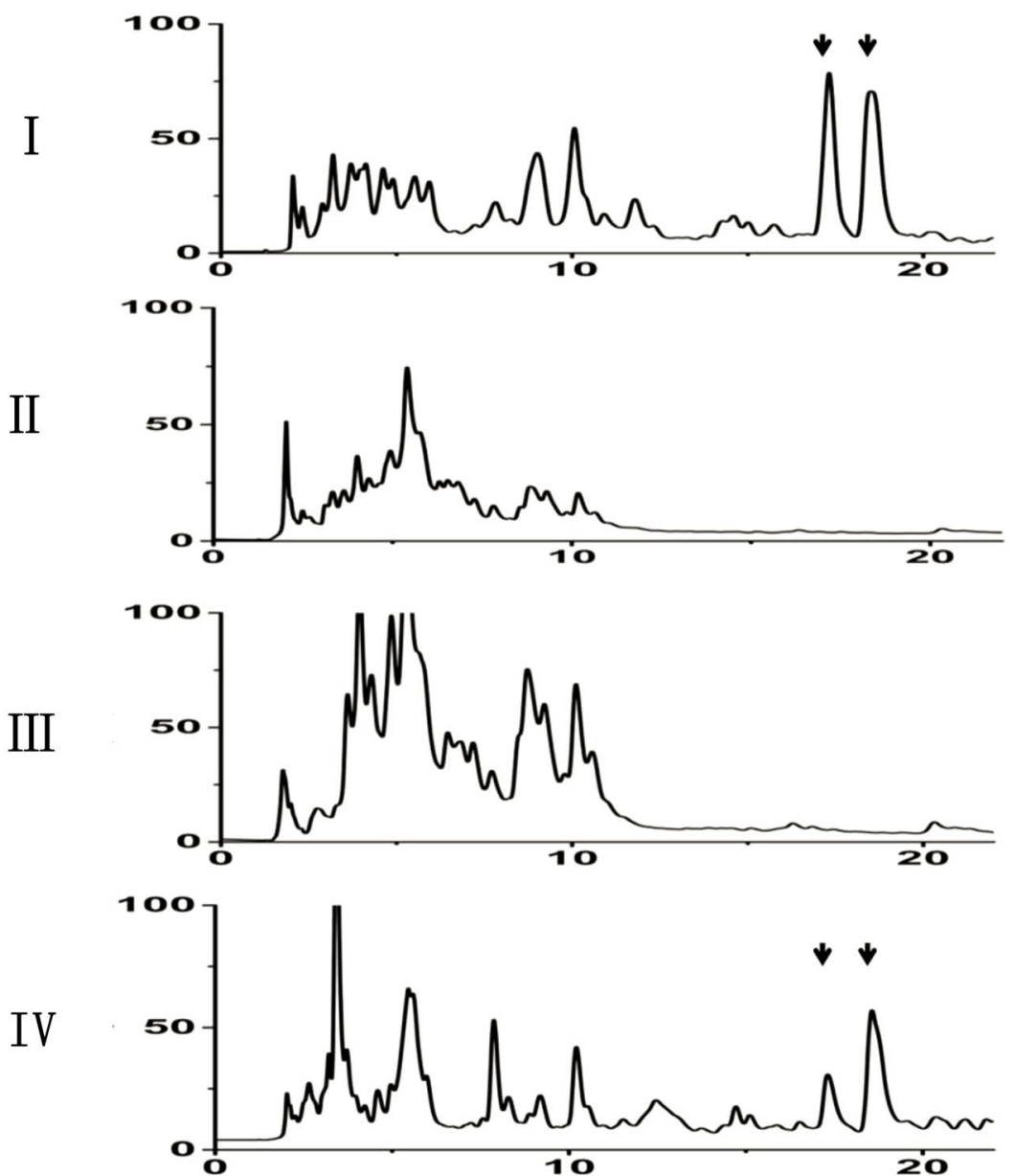

Fig. 3 Bioassays and HPLC analysis of the fermentation broth from S. ansochromogenes 7100 and $\triangle$ wblA. Bioassays of the fermentation broth against Staphylococcus aureus (a) and Bacillus cereus (b), and the HPLC analysis (c). (I): $\triangle$ wblA, (II): S. ansochromogenes 7100, (III): complemented strain by integrating a copy of $w b / A$ into the chromosome of $\triangle \mathrm{wbIA}$, (IV): the control strain by integrating pSET152 vector into the chromosome of $\triangle$ wblA. Arrows indicate the new appeared peaks on HPLC produced by $\triangle$ wblA

\section{Bioassays of compound 1 and 2}

Structural elucidation showed compound 1 and compound $\mathbf{2}$ are 16-membered glycosylated macrolides.
The functional groups responsible for the antibacterial activity of 16-membered macrolides are generally thought to be the aldehyde and the 9-keto group on 



Fig. 4 Identification of compound $\mathbf{1}$ and $\mathbf{2}$ produced by $\triangle$ wbIA. HPLC chromatograms (a) and the UV absorption spectra of compound $\mathbf{1}$ and $\mathbf{2}$ (b) (I): purified compound $\mathbf{1}$, (I): purified compound $\mathbf{2}$, (III): fermentation broth from $\triangle \mathrm{wblA}$

the lactone, dimethylamino or methoxyl group on the sugar moieties and ethyl group at position C15 (Fig. 5g) [18]. In preliminary assays performed by disk diffusion tests, the fermentation filtrate of $\Delta$ wblA showed inhibitory activity against gram-positive pathogenic bacteria (Additional file 1: Table S1). MIC (minimum inhibitory concentration) values were then determined with purified compound $\mathbf{1}$ and compound $\mathbf{2}$ against a variety of gram-positive bacteria using tylosin as a control, a 16-membered macrolide antibiotic usually used in the treatment for various infections of animals [19, 20]. Compound 1 showed identical antimicrobial activity as compound 2, but their activity was less than that of tylosin against most of the tested strains (Table 2). All three compounds could not inhibit the growth of Staphylococcus epidermidis at $100 \mu \mathrm{g} / \mathrm{ml}$. However, it is intriguing that compound $\mathbf{1}$ and compound $\mathbf{2}$ significantly inhibited the growth of S. pneumoniae and their MICs were more than ten folds lower than that of tylosin (Table 2). The results indicated that compound $\mathbf{1}$ and compound 2 are probably promising new derivatives of tylosin for further structural optimization.

\section{Discussion}

It is imperative to find novel families of antibiotics for tackling evolving pathogens. Streptomyces serves as the main source of antibiotics, despite most secondary metabolic pathways are silent or poorly expressed. Based on metabolic pathways and regulatory mechanisms of antibiotic biosynthesis, specific manipulation on key gene is feasible to redirect metabolic flux to the target metabolites, such as heterologous expression of the whole cluster, repressor deletion or activator enhancement, and so on. Those approaches enabled the discovery of numerous novel antibiotics [6]. However, a large proportion of secondary metabolic pathways in Streptomyces have not been unveiled. Therefore, it has become necessary to devise methods and strategies to identify these valuable secondary metabolites.

WblA of S. ansochromogenes 7100 shares $96 \%$ sequence identity with that of $S$. coelicolor, and is a new member of pleiotropic regulators. Disruption of $w b l A$ influenced the morphological differentiation and the production of antibiotics in many Streptomyces spp. [13, 14]. As expected, the disruption of $w b l A$ in S. ansochromogenes 


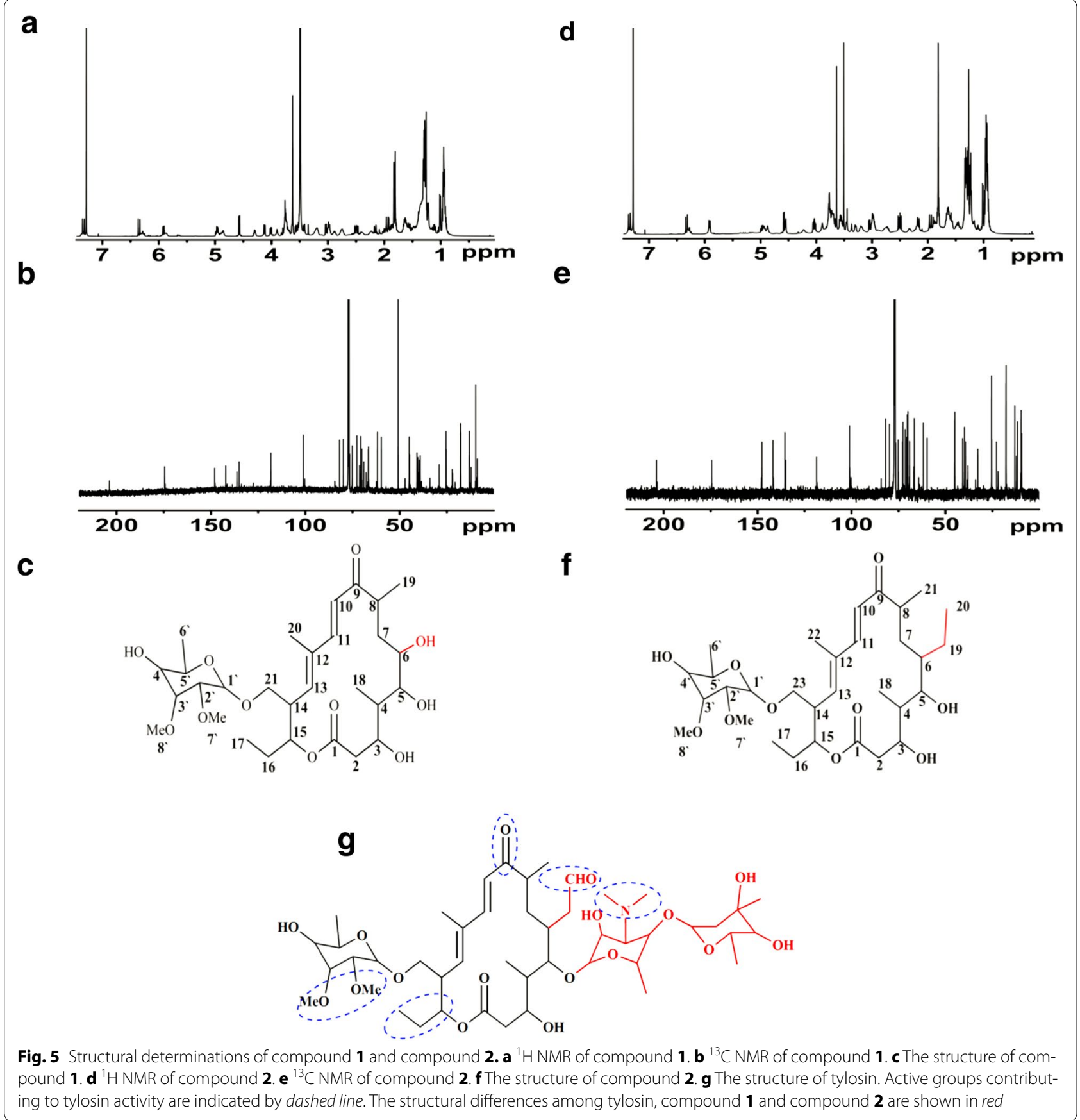

7100 influenced spore formation and also abolished nikkomycin production, but led to the biosynthesis of two novel tylosin analogues. WblA can serve as a down-regulator or activator depending on the species of the strain probably via the iron-sulfur cluster in the molecule for sensing environmental signals, such as $\mathrm{O}_{2}$ or nitric oxide [21, 22]. In S. ansochromogenes 7100, WblA exerted dual function in antibiotic biosynthesis, demonstrating that the regulators of this family play important roles. Other pleiotropic regulators widely exist in many species of Streptomyces, such as AdpA and BldA controlling more than one pathway [23, 24]. It is applicable to obtain new compounds from the cell secondary metabolite reservoir by disrupting a single pleiotropic gene without knowing details about the mechanism or the pathway of the metabolite biosynthesis. So far, exact regulatory mechanism of WblA and its orthologues regulating antibiotics biosynthesis are still unknown. 
Table 1 Summary of ${ }^{1} \mathrm{H}$ and ${ }^{13} \mathrm{C}$ NMR data for compound 1 and compound 2 in $\mathrm{CDCl}_{3}$

\begin{tabular}{|c|c|c|c|c|}
\hline \multirow[t]{2}{*}{ Position } & \multicolumn{2}{|l|}{ Compound 1} & \multicolumn{2}{|l|}{ Compound 2} \\
\hline & $\delta\left({ }^{1} \mathrm{H}\right.$, mult., J) & ${ }^{13} \mathrm{C}(\delta)$ & $\delta\left({ }^{1} \mathrm{H}\right.$, mult., J) & ${ }^{13} \mathrm{C}(\delta)$ \\
\hline 1 & & 174.7 & & 174.7 \\
\hline 2 & $\begin{array}{l}1.92(1 \mathrm{H}, \mathrm{d}, 16) \\
2.5(1 \mathrm{H}, \mathrm{dd}, 17,10.7)\end{array}$ & 39.2 & $\begin{array}{l}1.92(1 \mathrm{H}, \mathrm{d}, 16) \\
2.5(1 \mathrm{H}, \mathrm{dd}, 17,10.7)\end{array}$ & 39.2 \\
\hline 3 & $3.72(1 \mathrm{H}, \mathrm{d}, 10.0)$ & 67.1 & $3.72(1 \mathrm{H}, \mathrm{d}, 10.0)$ & 66.8 \\
\hline 4 & $1.48\left(1 \mathrm{H}^{*}\right)$ & 39.9 & $1.48\left(1 \mathrm{H}^{*}\right)$ & 39.9 \\
\hline 5 & $4.1(1 \mathrm{H}, \mathrm{d}, 13.0)$ & 71.6 & $3.77(1 \mathrm{H}, \mathrm{d}, 9.0)$ & 72.6 \\
\hline 6 & $4.3\left(1 \mathrm{H}^{*}{ }^{*}\right)$ & 67.9 & $1.3\left(1 \mathrm{H},{ }^{*}\right)$ & 38 \\
\hline 7 & $\begin{array}{l}2.0(1 \mathrm{H}, \mathrm{m}) \\
1.56\left(1 \mathrm{H}^{*}\right)\end{array}$ & 29.2 & $\begin{array}{l}1.42(1 \mathrm{H}, \mathrm{m}) \\
1.57\left(1 \mathrm{H}^{*}{ }^{*}\right)\end{array}$ & 32.7 \\
\hline 8 & $2.8(1 \mathrm{H}, \mathrm{br})$ & 45.1 & $2.7(1 \mathrm{H}, \mathrm{br})$ & 45.1 \\
\hline 9 & & 204 & & 204 \\
\hline 10 & $6.34(1 \mathrm{H}, \mathrm{d}, 15.0)$ & 118.3 & $6.33(1 \mathrm{H}, \mathrm{d}, 15.0)$ & 118.6 \\
\hline 11 & $7.32(1 \mathrm{H}, \mathrm{d}, 15.0)$ & 148.1 & $7.32(1 \mathrm{H}, \mathrm{d}, 15.0)$ & 147.8 \\
\hline 12 & & 135.1 & & 135.5 \\
\hline 13 & $5.92(1 \mathrm{H}, \mathrm{d}, 10.0)$ & 141.9 & $5.92(1 \mathrm{H}, \mathrm{d}, 10.0)$ & 141.7 \\
\hline 14 & $2.98(1 \mathrm{H}, \mathrm{m})$ & 45.1 & $2.98(1 \mathrm{H}, \mathrm{m})$ & 45.1 \\
\hline 15 & $\begin{array}{l}4.98(1 \mathrm{H}, \mathrm{ddd}, 10.0 \\
10.0,2.0)\end{array}$ & 75.3 & $\begin{array}{l}4.98(1 \mathrm{H}, \mathrm{ddd}, 10.0 \\
10.0,2.0)\end{array}$ & 75.2 \\
\hline 16 & $\begin{array}{l}1.88(1 \mathrm{H}, \mathrm{m}) \\
1.63(1 \mathrm{H}, *)\end{array}$ & 25.4 & $\begin{array}{l}1.88(1 \mathrm{H}, \mathrm{m}) \\
1.63(1 \mathrm{H}, *)\end{array}$ & 25.5 \\
\hline 17 & $0.94\left(3 \mathrm{H}^{*}\right)$ & 9.5 & $0.94\left(3 \mathrm{H}_{,}^{*}\right)$ & 9.5 \\
\hline 18 & $1.0(3 \mathrm{H}, \mathrm{d}, 6.0)$ & 9.5 & $1.0(3 \mathrm{H}, \mathrm{d}, 6.0)$ & 9.6 \\
\hline 19 & $1.22(3 \mathrm{H}, \mathrm{d}, 7.0)$ & 17.6 & $\begin{array}{l}1.62\left(1 \mathrm{H}^{*}\right) \\
1.3\left(1 \mathrm{H}^{*}\right)\end{array}$ & 22.7 \\
\hline 20 & $1.81(3 \mathrm{H}, \mathrm{s})$ & 13.2 & $0.92\left(3 \mathrm{H},{ }^{*}\right)$ & 9.4 \\
\hline 21 & $\begin{array}{l}4.01(1 \mathrm{H}, \mathrm{dd}, 9.0,4.0) \\
3.55\left(1 \mathrm{H},{ }^{*}\right)\end{array}$ & 69.1 & $1.23(3 \mathrm{H}, \mathrm{d}, 7.0)$ & 17.6 \\
\hline 22 & & & $1.81(3 \mathrm{H}, \mathrm{s})$ & 13.2 \\
\hline 23 & & & $\begin{array}{l}4.01(1 \mathrm{H}, \mathrm{dd}, 9.0,4.0) \\
3.55\left(1 \mathrm{H},{ }^{*}\right)\end{array}$ & 69 \\
\hline 1 & $4.58(1 \mathrm{H}, \mathrm{d}, 7.5)$ & 101.1 & $4.58(1 \mathrm{H}, \mathrm{d}, 7.5)$ & 101.1 \\
\hline 2 & $3.04(1 \mathrm{H}, \mathrm{dd}, 7.5,2.5)$ & 81.5 & $3.04(1 \mathrm{H}, \mathrm{dd}, 7.5,2.5)$ & 81.5 \\
\hline 3 & $3.77(1 \mathrm{H}, \mathrm{d}, 9.0)$ & 79.8 & $3.77(1 \mathrm{H}, \mathrm{d}, 9.0)$ & 79.8 \\
\hline 4 & $3.2(1 \mathrm{H}, \mathrm{m})$ & 72.6 & $3.2(1 \mathrm{H}, \mathrm{m})$ & 72.6 \\
\hline $5^{\prime}$ & $3.53\left(1 \mathrm{H},{ }^{*}\right)$ & 70.5 & $3.53\left(1 \mathrm{H},{ }^{*}\right)$ & 70.5 \\
\hline 6 & $1.29(3 \mathrm{H}, *)$ & 17.7 & $1.29(3 \mathrm{H}, *)$ & 17.7 \\
\hline $7^{\prime}$ & $3.5(3 \mathrm{H}, \mathrm{s})$ & 59.7 & $3.5(3 \mathrm{H}, \mathrm{s})$ & 59.7 \\
\hline 8 & $3.63(3 \mathrm{H}, \mathrm{s})$ & 61.9 & $3.63(3 \mathrm{H}, \mathrm{s})$ & 61.9 \\
\hline
\end{tabular}

In this table, $s$ singlet, $d$ doublet, $m$ multiplet, $b r$ broad

* Overlapping with other signals

Structure determination revealed that compound $\mathbf{1}$ and compound $\mathbf{2}$ are tylosin analogues. Tylosin can inhibit bacterial growth by binding to the large ribosomal subunit to block the peptide tunnel [25]. Despite the structure difference at C6, compound $\mathbf{1}$ and compound $\mathbf{2}$ showed similar antibacterial activity, indicating that ethyl group
Table 2 Antimicrobial activities of compound 1, 2 and tylosin

\begin{tabular}{llll}
\hline Bacteria & MIC $(\boldsymbol{\mu g} / \mathbf{m l})$ & & \\
\cline { 2 - 4 } & Compound 1 & Compound 2 & Tylosin \\
\hline Streptococcus pneumoniae & 7.06 & 7.31 & $>100$ \\
Streptococcus pyogenes & 3.53 & 3.65 & 0.2 \\
Staphylococcus epidermidis & $>100$ & $>100$ & $>100$ \\
Staphylococcus aureus & 56.5 & 58.5 & 0.4 \\
Bacillus subtilis & 14.1 & 14.6 & 0.4 \\
Bacillus cereus & 28.2 & 29.2 & 0.4 \\
\hline
\end{tabular}

at $\mathrm{C} 6$ position is replaceable with hydroxyl group without compromising the antibacterial activity (Fig. 5g). Compared to tylosin, the activity of compound $\mathbf{1}$ and compound $\mathbf{2}$ against most indicator strains was much lower. The reduction in activity of these compounds may be resulted from the absence of some active groups contributing to the tylosin activity, such as the aldehyde at C6 position, dimethyl amino as well as the saccharide moieties at C5 (Fig. 5c, f). No inhibitory activity against Staphylococcus epidermidis was observed with compound 1, compound 2 and tylosin at $100 \mu \mathrm{g} / \mathrm{ml}$. However, very interestingly, compound $\mathbf{1}$ and compound $\mathbf{2}$ exhibited much higher activity against Streptococcus pneumoniae than tylosin (Table 2). S. pneumoniae strain with certain resistance to tylosin is probably due to the evolvement of pathogenic strains. Ribosome mutation is one way to obtain resistance to ribosome-targeted drugs. It was reported that replacing G2099 of ribosome with dimethyl adenine in Haloarcula marismortui triggered sterically clashing with dimethyl amino group linked to the saccharide moieties of tylosin and then the resistance was induced [26]. For compound $\mathbf{1}$ and compound 2 , the reduced molecular size lacking dimethyl amino and saccharide branch at $\mathrm{C} 5$ could be beneficial for the compound to be accommodated into the ribosome tunnel of pathogenic strains. These results suggested that compound 1 and compound $\mathbf{2}$ could serve as starting molecules for further structural optimization to produce diverse bioactive agents, which are constantly required to combat the evolving pathogens and new diseases.

\section{Conclusions}

Two novel tylosin analogues were generated by $\Delta$ wblA. Interestingly, the activity of compound $\mathbf{1}$ and compound 2 against S. pneumoniae was much higher than that of tylosin. They might serve as new derivatives of tylosin for property improvement by engineering combinatorial biosynthesis of metabolic pathways. 


\section{Methods}

\section{Strains, plasmids, primers and growth conditions}

Strains and plasmids used in this study are listed in Table 3, and the primers used in this study are listed in Table 4. Streptomyces ansochromogenes 7100, a natural nikkomycin producer, and its derivatives were grown at $28{ }^{\circ} \mathrm{C}$. SP medium (3\% mannitol, $1 \%$ soluble starch, $0.75 \%$ yeast extract and $0.5 \%$ soy peptone, $\mathrm{pH}$ 6.0) was prepared for the production of antibiotics as described previously [27]. Agar minimal medium (MM) supplemented with mannitol as sole carbon source for sporulation was prepared [28]. Escherichia coli JM109, routinely used as a host for propagation of plasmids, was grown in Luria-Bertani (LB) medium at $37{ }^{\circ} \mathrm{C}$. ET12567/pUZ8002 was used for conjugal transfer of DNA from E. coli to Streptomyces [28]. Tylosin tartrate was purchased from Sigma Aldrich, and used as a control in bioassays. All fungal strains used as indicators in this study except $C$. albicans were incubated for 5 days in PDA at $28^{\circ} \mathrm{C}$. C. albicans was grown in PDA for overnight at $37^{\circ} \mathrm{C}$.

\section{Construction of recombinant strains}

To construct the $w b l A$ disruption mutant $(\Delta \mathrm{wblA})$ of $S$. ansochromogenes 7100, the DNA fragment corresponding to the upstream region of $w b l A$ was amplified by PCR using primers LwblA-F and LwblA-R, and then it was digested with HindIII and XbaI. The pwblA1 was constructed by inserting above PCR product into the same sites of pKC1139. The DNA fragment corresponding to the downstream region of $w b l A$ was amplified by PCR using primers RwblA-F and RwblA-R, followed by digestion with $B a m \mathrm{HI}$ and EcoRV and inserted into the same sites of pwblA1 to generate pwblA2. Kanamycin resistance gene was amplified by PCR using primers Kan-F and Kan-R followed by digestion with $\mathrm{BamHI}$ and $\mathrm{XbaI}$, and inserted into the same sites of pwblA2 to generate pwblA3. Subsequently, pwblA3 was introduced into $S$. ansochromogenes 7100 via ET12567/pUZ8002 by conjugal transfer. The transformants resistant to kanamycin $\left(\operatorname{Kan}^{r}\right)$ but sensitive to apramycin $\left(\mathrm{Apr}^{\mathrm{S}}\right)$ were selected and further confirmed by PCR using primers wblAJ-F and wblAJ-R. For complementation analysis, the fragment containing the intact $w b l A$ with its putative promoter region was amplified using primers CwblA-F and CwblA-R, and inserted into the EcoRV site of pSET152 to generate pSET152::wblA. Subsequently, pSET152::wblA was introduced into $\Delta$ wblA by conjugal transfer, and the resulting complemented strain was further confirmed by PCR. The null mutant was constructed by integrating pSET152 vector into the chromosome of $\Delta w b l A$ as a control. All PCR amplicons were confirmed by sequencing.

Table 3 Strains and plasmids used in this study

\begin{tabular}{|c|c|c|}
\hline Name & Description & Sources \\
\hline \multicolumn{3}{|l|}{ Strains } \\
\hline S. ansochromogenes 7100 & Wild-type strain & {$[27]$} \\
\hline$\Delta \mathrm{wblA}$ & $\begin{array}{l}\text { The ORF of wh/A consists of } 339 \mathrm{bp} \text {, and } 230 \mathrm{bp} \text { of them was } \\
\text { replaced by kanamycin resistance gene (neo) }\end{array}$ & This study \\
\hline$\triangle w b \mid A / p S E T 152:: w b / A$ & The complemented strain of $\Delta \mathrm{wblA}$ & This study \\
\hline Escherichia coli JM109 & $\begin{array}{l}\text { recA1, endA1, gyrA96, thi-1, hsdR17, supE44, relA1, } \triangle(\text { lac-proAB }) / F^{\prime} \\
{[\operatorname{traD} 36, \text { pro } A B+\text { laclq, lacZ } \triangle M 15]}\end{array}$ & Invitrogen \\
\hline Escherichia coli ET12567/pUZ8002 & dam dcm hsdS cat tet/pUZ8002 & {$[31]$} \\
\hline Staphylococcus aureus CGMCC1.89 & Indicator strain for bioassays & CGMCC \\
\hline Bacillus subtilis CGMCC 1.1630 & Indicator strain for bioassays & CGMCC \\
\hline Bacillus cereus CGMCC 1.1626 & Indicator strain for bioassays & CGMCC \\
\hline Candida albicans CGMCC2.4159 & Indicator strain for bioassays & CGMCC \\
\hline Alternaria longipes CGMCC3.2946 & Indicator strain for bioassays & CGMCC \\
\hline \multicolumn{3}{|l|}{ Plasmids } \\
\hline pwblA-DM & Plasmid used for the construction of $\Delta \mathrm{wbl} A$ & This study \\
\hline pSET152:: wbIA & pSET152 containing the intact wblA with its putative promoter & This study \\
\hline pSET152 & Integrative vector & {$[32]$} \\
\hline pKC1139 & E. coli-Streptomyces shuttle vector & {$[28]$} \\
\hline pBluescript KS+ & Routine cloning and subcloning vector & Stratagene \\
\hline
\end{tabular}

CGMCC China General Microbiological Culture Collection Center 
Table 4 Primers used in this study

\begin{tabular}{|c|c|}
\hline Primers & Sequence $\left(5^{\prime}-3^{\prime}\right)$ \\
\hline \multicolumn{2}{|c|}{ Primers for gene disruption and complementation } \\
\hline LwblA-F & AAGCTTTCGGGTACGCCATCTCGTA \\
\hline LwblA-R & TCTAGAGCTGCTCCCTGAACGAACA \\
\hline RwblA-F & GGATCCACGACGAGGTGTACGAGAAC \\
\hline RwblA-R & GATATCTGACGCTGCTGGAGGAGAT \\
\hline Kan-F & TCTAGAGATCCCCTGGATACCGCTCG \\
\hline Kan-R & GGATCCGTACCCGAACCCCAGAGTC \\
\hline WblAJ-F & AACTGGCGGCGGTGAATA \\
\hline wblAJ-R & ACGGACGGAGCACATATAGG \\
\hline CwblA-F & GGATCCGCCTGAACGGACGGAGCACATA \\
\hline CwblA-R & TCTAGAAGCACACTGACACCGAGGAACTTGGC \\
\hline \multicolumn{2}{|c|}{ Primers for qRT-PCR } \\
\hline RTsanG-F & GGCGTACACAGCTCAAGAGC \\
\hline RTsanG-R & AATTCGTCGATGAGCTGATC \\
\hline RTsanN-F & AGATCATGCGCTCGGACTGT \\
\hline $\mathrm{RTsanN-R}$ & TGGCGTGCAGGATCGGTA \\
\hline RTsanO-F & ACTGCGATCCGTGGTCAA \\
\hline RTsanO-R & TGTACTCCAGGCACTCCC \\
\hline RTsanF-F & CGGCGCTGGAGGAACGTAC \\
\hline RTsanF-R & GGGTGTAGAGGCCGATGCT \\
\hline RThrdB-F & GCTGGCCAAGGAACTCGACAT \\
\hline RThrdB-R & CGAAGCGCATGGAGACGACG \\
\hline
\end{tabular}

\section{RNA isolation and qRT-PCR}

Total RNA was isolated from Streptomyces, and quantitative Real Time PCR (qRT-PCR) was performed as described previously [29].

\section{Microscopy}

For scanning electron microscopy, colonies were fixed in $2.5 \%(\mathrm{v} / \mathrm{v})$ glutaraldehyde for $4 \mathrm{~h}$, stained with osmic acid for 2-4 $\mathrm{h}$ and dehydrated with ethanol at different concentrations. Each sample was coated with platinum-gold and then examined with a Hitachi D-570 scanning microscope.

\section{Detection of nikkomycin and tylosin analogues}

Nikkomycin was detected by disk agar diffusion and HPLC as previously described [30]. The detection of tylosin analogues was performed by HPLC on an Agilent 1260 system equipped with a ZORBAX SB-C18 reverse phase column $(4.6 \times 250 \mathrm{~mm}, 5 \mu \mathrm{m}$, Agilent). Samples were eluted at $1 \mathrm{ml} / \mathrm{min}$ with a linear gradient from 50 to $80 \%$ of methanol in water over $25 \mathrm{~min}$ at wavelength of $280 \mathrm{~nm}$. Each experiment was performed in triplicate.

\section{Isolation and structural determination of compound 1 and 2}

For antibiotics production, spore suspensions were inoculated into liquid SP medium and cultured at $28{ }^{\circ} \mathrm{C}$ for
$24 \mathrm{~h}$ as seed culture in shake flask (220 revolutions per minute, rpm), and then $30 \mathrm{ml}$ of seed culture was transferred to $3 \mathrm{~L}$ of SP in a $5 \mathrm{~L}$ fermentor (BIOTECH-5JG, $\mathrm{BX}-\mathrm{BIO})$. BIOTECH-FCS software was used to control the equipment and collect data. Air was sparged into the fermentor to supply oxygen at four times atmospheric pressure, and the rotor speed was $400 \mathrm{rpm}$. After fermentation for 5 days at $28{ }^{\circ} \mathrm{C}$ the culture broth of $\triangle$ wblA was filtered by Pyrex Buchner funnel with a fritted disc (pore size 40-60 mm). Then the supernatant was extracted by separatory funnel with equal volume of chloroform for three times at room temperature. Chloroform extract was evaporated to dry. The resulting sample was re-dissolved in methanol and then separated on Sephadex LH-20 as mentioned above. Active fractions were collected and purified by semi-preparative HPLC equipped with ZORBAX SB-C18 reverse phase column $(9.4 \times 250 \mathrm{~mm}, 5 \mu \mathrm{m}$, Agilent $)$ by linear gradient elution as mentioned above.

MS analysis was performed on LTQ Orbitrap hybrid mass spectrometer (Thermo-Fisher) equipped with a Dionex Ultimate 3000 nano-flow system and a nanoelectrospray ion source. NMR spectra were recorded on a $500 \mathrm{MH}_{\mathrm{Z}}$ Bruker spectrometer using $\mathrm{CDCl}_{3}$ as the solvent.

\section{Determination of minimum inhibitory concentration (MIC)}

Compound 1, 2 and tylosin standard were dissolved in DMSO and serially diluted with LB prior to mixing with indicator strains. Indicator strains were pre-incubated in LB on a rotary shaker at $37{ }^{\circ} \mathrm{C}$ for overnight. Assays for determining MIC were performed on 96-well plates consisting of the diluted compounds, indicator strains $(0.5 \%)$ and $0.5 \%$ DMSO. Strains growing in LB medium containing $0.5 \%$ DMSO without test compounds were used as positive controls, and LB medium containing $0.5 \%$ DMSO was used as negative control. The growth of indicator strains was measured after $12 \mathrm{~h}$ of incubation for S. epidermidis, S. aureus, B. subtilis and B. cereus, and $24 \mathrm{~h}$ for $S$. pneumoniae and $S$. pyogenes on a microplate reader (Synergy H4, Biotech) at wavelength of $600 \mathrm{~nm}$. Each experiment was performed in triplicate.

\section{Additional file}

Additional file 1. Figure S1. NMR Spectra of compound 1. (A) Summary of key correlations between protons and carbons in compound $\mathbf{1}$ based on NMR spectroscopic data. (B) ${ }^{1} \mathrm{H}-{ }^{1} \mathrm{H}$ COSY spectrum of compound $\mathbf{1}$ (C) ${ }^{1} \mathrm{H}-^{13} \mathrm{C}$ HSQC spectrum of compound 1. (D) ${ }^{1} \mathrm{H}^{-13} \mathrm{C} \mathrm{HMBC}$ spectrum of compound 1. Figure S2. NMR Spectra of compound $\mathbf{2}$. (A) Summary of key correlations between protons and carbons in compound $\mathbf{2}$ based on NMR spectroscopic data. (B) ${ }^{1} \mathrm{H}-{ }^{1} \mathrm{H}$ COSY spectrum of compound $\mathbf{2}$ (C) ${ }^{1} \mathrm{H}^{13} \mathrm{C} \mathrm{HSQC}$ spectrum of compound $\mathbf{2}$. (D) ${ }^{1} \mathrm{H}^{13} \mathrm{C}$ HMBC spectrum of compound $\mathbf{2}$. Table $\mathbf{S 1}$. Antimicrobial activities of fermentation broth from S. ansochromogenes 7100 and $\triangle \mathrm{wb}$ A by agar diffusion assays. 


\section{Authors' contributions}

$\mathrm{CL}$ carried out experiments and analyzed the primary data. GL constructed the wblA mutant strain. JZ wrote and revised the manuscript. HT supervised the whole research work and revised the manuscript. All authors read and approved the final manuscript.

\section{Author details}

${ }^{1}$ State Key Laboratory of Microbial Resources, Institute of Microbiology, Chinese Academy of Sciences, Beijing 100101, China. ${ }^{2}$ University of Chinese Academy of Sciences, Beijing 100049, China. ${ }^{3}$ College of Pharmaceutical Sciences, Southwest University, Chongqing 400715, China.

\section{Acknowledgements}

This work was supported by grants from the Ministry of Science and Technology of China (Grant nos. 2015CB150600 and 2013CB734001) and the National Natural Science Foundation of China (Grant nos. 31270110 and 31370097 ). We are grateful to Dr Zhoujie Xie, Professor Luyan Ma and Professor Baoshan Chen for kindly providing strains (Streptococcus pneumoniae 010, Streptococcus pyogenes \#2, Staphylococcus epidermidis ATCC 35984, Pseudomonas aeruginosa PA14, Sporisorium scitamineum JG35, Cryphonectria parasitica EP155 and Magnaporthe grisea Y34). We thank Drs Guomin Ai and Jinwei Ren (the Institute of Microbiology, Chinese Academy of Sciences, Beijing, China) for assistance with Mass Spectrometry (MS) and Nuclear Magnetic Resonance (NMR) Spectroscopy.

\section{Competing interests}

The authors declare that they have no competing interests.

Received: 15 June 2015 Accepted: 8 October 2015

Published online: 02 November 2015

\section{References}

1. Du D, Wang L, Tian Y, Liu H, Tan H, Niu G. Genome engineering and direct cloning of antibiotic gene clusters via phage $\Phi B T 1$ integrase-mediated site-specific recombination in Streptomyces. Sci Rep. 2015;5:8740.

2. Li J, Li L, Feng C, Chen Y, Tan H. Novel polyoxins generated by heterologously expressing polyoxin biosynthetic gene cluster in the sanN inactivated mutant of Streptomyces ansochromogenes. Microb Cell Fact. 2012;11:135.

3. Feng C, Ling H, Du D, Zhang J, Niu G, Tan H. Novel nikkomycin analogues generated by mutasynthesis in Streptomyces ansochromogenes. Microb Cell Fact. 2014;13:59.

4. Bentley SD, Chater KF, Cerdeno-Tarraga AM, Challis GL, Thomson NR, James KD, Harris DE, Quail MA, Kieser H, Harper D, et al. Complete genome sequence of the model actinomycete Streptomyces coelicolor A3(2). Nature. 2002:417:141-7.

5. Ohnishi Y, Ishikawa J, Hara H, Suzuki H, Ikenoya M, Ikeda H, Yamashita A, Hattori M, Horinouchi S. Genome sequence of the streptomycinproducing microorganism Streptomyces griseus IFO 13350. J Bacteriol. 2008; 190:4050-60.

6. Liu G, Chater KF, Chandra G, Niu G, Tan H. Molecular regulation of antibiotic biosynthesis in Streptomyces. Microbiol Mol Biol Rev. 2013;77:112-43.

7. Zhong X, Tian Y, Niu G, Tan H. Assembly and features of secondary metabolite biosynthetic gene clusters in Streptomyces ansochromogenes. Sci China Life Sci. 2013;56:609-18.

8. Chater KF. Regulation of sporulation in Streptomyces coelicolor A3(2): a checkpoint multiplex? Curr Opin Microbiol. 2001;4:667-73.

9. Fowler-Goldsworthy K, Gust B, Mouz S, Chandra G, Findlay KC, Chater KF. The actinobacteria-specific gene wblA controls major developmental transitions in Streptomyces coelicolor A3(2). Microbiology. 2011;157:1312-28.

10. Davis NK, Chater KF. The Streptomyces coelicolor whiB gene encodes a small transcription factor-like protein dispensable for growth but essential for sporulation. Mol Gen Genet. 1992;232:351-8.

11. Noh JH, Kim SH, Lee HN, Lee SY, Kim ES. Isolation and genetic manipulation of the antibiotic down-regulatory gene, wblA ortholog for doxorubicin-producing Streptomyces strain improvement. Appl Microbiol Biotechnol. 2010;86:1145-53.

12. Nah JH, Park SH, Yoon HM, Choi SS, Lee CH, Kim ES. Identification and characterization of wblA-dependent $t m c T$ regulation during tautomycetin biosynthesis in Streptomyces sp CK4412. Biotechnol Adv. 2012;30:202-9.

13. Rabyk M, Ostash B, Rebets Y, Walker S, Fedorenko V. Streptomyces ghanaensis pleiotropic regulatory gene wblA (gh) influences morphogenesis and moenomycin production. Biotechnol Lett. 2011;33:2481-6.

14. Yu P, Liu S, Bu Q, Zhou Z, Zhu Z, Huang F, Li Y. WblAch, a pivotal activator of natamycin biosynthesis and morphological differentiation in Streptomyces chattanoogensis $\mathrm{L} 10$, is positively regulated by AdpAch. Appl Environ Microbiol. 2014;80:6879-87.

15. Niu G, Tan H. Nucleoside antibiotics: biosynthesis, regulation, and biotechnology. Trends Microbiol. 2015;23:110-9.

16. Liu G, Tian Y, Yang H, Tan H. A pathway-specific transcriptional regulatory gene for nikkomycin biosynthesis in Streptomyces ansochromogenes that also influences colony development. Mol Microbiol. 2005;55:1855-66.

17. Morisaki N, Hashimoto Y, Furihata K, Yazawa K, Tamura M, Mikami Y. Glycosylative inactivation of chalcomycin and tylosin by a clinically isolated Nocardia asteroides strain. J Antibiot (Tokyo). 2001;54:157-65.

18. Omura S, Tishler M. Relationship of structures and microbiological activities of the 16-membered macrolides. J Med Chem. 1972;15:1011-5.

19. Simpson KW, Jergens AE. Pitfalls and progress in the diagnosis and management of canine inflammatory bowel disease. Vet Clin North Am Small Anim Pract. 2011:41:381-98.

20. Westermarck E, Wiberg M. Exocrine pancreatic insufficiency in the dog: historical background, diagnosis, and treatment. Top Companion Anim Med. 2012;27:96-103.

21. Crack JC, Smith LJ, Stapleton MR, Peck J, Watmough NJ, Buttner MJ, Buxton RS, Green J, Oganesyan VS, Thomson AJ, Le Brun NE. Mechanistic insight into the nitrosylation of the [4Fe-4S] cluster of WhiB-like proteins. J Am Chem Soc. 2011;133:1112-21.

22. Larsson C, Luna B, Ammerman NC, Maiga M, Agarwal N, Bishai WR. Gene expression of Mycobacterium tuberculosis putative transcription factors WhiB1-7 in redox environments. PLoS One. 2012;7:37516.

23. Kalan L, Gessner A, Thaker MN, Waglechner N, Zhu X, Szawiola A, Bechthold A, Wright GD, Zechel DL. A cryptic polyene biosynthetic gene cluster in Streptomyces calvus is expressed upon complementation with a functional bldA gene. Chem Biol. 2013;20:1214-24.

24. Guyet A, Benaroudj N, Proux C, Gominet M, Coppee JY, Mazodier P. Identified members of the Streptomyces lividans AdpA regulon involved in differentiation and secondary metabolism. BMC Microbiol. 2014;14:81.

25. McCoy LS, Xie Y, Tor Y. Antibiotics that target protein synthesis. Wiley Interdiscip Rev RNA. 2011;2:209-32.

26. Hansen JL, Ippolito JA, Ban N, Nissen P, Moore PB, Steitz TA. The structures of four macrolide antibiotics bound to the large ribosomal subunit. Mol Cell. 2002;10:117-28.

27. Zeng $H$, Tan H, Li J. Cloning and function of san Q: a gene involved in nikkomycin biosynthesis of Streptomyces ansochromogenes. Curr Microbiol. 2002:45:175-9.

28. Kieser T, Bibb MJ, Buttner MJ, Chater KF, Hopwood DA. Practical Streptomyces genetics. Norwich: John Innes Foundation; 2000.

29. Du D, Zhu Y, Wei J, Tian Y, Niu G, Tan H. Improvement of gougerotin and nikkomycin production by engineering their biosynthetic gene clusters. Appl Microbiol Biotechnol. 2013;97:6383-96.

30. Liao G, Li J, Li L, Yang H, Tian Y, Tan H. Selectively improving nikkomycin $Z$ production by blocking the imidazolone biosynthetic pathway of nikkomycin $\mathrm{X}$ and uracil feeding in Streptomyces ansochromogenes. Microb Cell Fact. 2009;8:61.

31. Paget MS, Chamberlin L, Atrih A, Foster SJ, Buttner MJ. Evidence that the extracytoplasmic function sigma factor $\xi^{E}$ is required for normal cell wall structure in Streptomyces coelicolor A3(2). J Bacteriol. 1999;181:204-11.

32. Bierman M, Logan R, O'Brien K, Seno ET, Rao RN, Schoner BE. Plasmid cloning vectors for the conjugal transfer of DNA from Escherichia coli to Streptomyces spp. Gene. 1992;116:43-9. 